\title{
COSMOLOGICAL PARAMETERS FROM THE CERES PROJECT
}

\author{
A. BIGGS, I.W.A. BROWNE, P. HELBIG, N.J. JACKSON, L. KING, \\ D.R. MARLOW, A. MCGUINNESS, S. NAIR, C.M. SYKES, P.N. WILKINSON AND \\ E. XANTHOPOULOS \\ University of Manchester, Nuffield Radio Astronomy Laboratories, \\ Jodrell Bank, Macclesfield, UK-Cheshire SK11 9DL, England
}

A.G. DE BRUYN

Netherlands Foundation for Research in Astronomy, P.O. Box 2, NL-7990 AA Dwingeloo, The Netherlands

R. BLANDFORD, J. COHEN, C. FASSNACHT, T. PEARSON, A. READHEAD AND

D. WOMBLE

California Institute of Technology, USA-Pasadena, CA 91125

M. BREMER AND G. MILEY

University of Leiden, Leiden Observatory, P.O. Box 9513, NL-2300 RA Leiden, The Netherlands

L. KOOPMANS

University of Groningen, Kapteyn Astronomical Institute, Postbus 800, NL-9700 AV Groningen, The Netherlands

S. MYERS

University of Pennsylvania, Dept. of Astronomy and Astrophysics, 209 S. $33^{\text {rd }}$ Street, USA-Philadelphia, PA 19104-6394

AND

A. PATNAIK

Max Planck Institute for Radioastronomy, Auf dem Hügel 69, D-53121 Bonn, Germany

The full poster is available at

http://multivac.jb.man.ac.uk:8000/ceres/papers/papers.html\#iau183pc

This research was supported in part by the European Commission, TMR Programme, Research Network Contract ERBFMRXCT96-0034 'CERES'. 